\title{
Reduced Length of Hospital Stay in Colorectal Surgery after Implementation of an Enhanced Recovery Protocol.
}

\author{
1. Author: Timothy E. Miller, MB, ChB, FRCA \\ - Title: Assistant Professor \\ - Affiliation: Department of Anesthesiology, Duke University Medical Center, \\ Durham, NC \\ - Email: timothy.miller2@dm.duke.edu \\ - Contribution: This author helped with study design, conduct of the study, \\ data analysis and manuscript preparation. \\ - Attestation: Timothy Miller approved the final manuscript, attests to the \\ integrity of the original data and the analysis reported in this manuscript, \\ and is the archival author. \\ - Conflict of interest: Consultant for Edwards Lifesciences, Covidien, and \\ Hospira. Research funding from Cheetah Medical and Retia Medical.
}

2. Author: Julie K. Thacker, MD

- Title: Assistant Professor

- Affiliation: Department of Surgery, Duke University Medical Center, Durham, NC

- Email: Julie.thacker@dm.duke.edu

- Contribution: This author helped with study design, data collection and conduct of the study

- Attestation: Julie Thacker approved the final manuscript

- Conflict of interest: None

3. Author: William D. White, MPH

- Title: Biostatistician

- Affiliation: Department of Anesthesiology, Duke University Medical Center, Durham, NC

- Email: william.d.white@dm.duke.edu

- Contribution: This author helped with data analysis and manuscript preparation.

- Attestation: William White approved the final manuscript

- Conflict of interest: None

4. Author: Christopher Mantyh, MD

- Title: Professor

- Affiliation: Department of Surgery, Duke University Medical Center, Durham, NC

- Email: christopher.mantyh@dm.duke.edu

- Contribution: This author helped conduct of the study

- Attestation: Christopher Mantyh approved the final manuscript

- Conflict of interest: None 
5. Author: John Migaly, MD

- Title: Assistant Professor

- Affiliation: Department of Surgery, Duke University Medical Center, Durham, NC

- Email: john.migaly@dm.duke.edu

- Contribution: This author helped with conduct of the study

- Attestation: John Migaly approved the final manuscript

- Conflict of interest: None

6. Author: Juying Jin, MD

- Title: Associate in Research

- Affiliation: Department of Anesthesiology, Duke University Medical Center, Durham, NC

- Current Affiliation: Anesthesiology Department of the First Affiliated Hospital of Chongqing Medical University, Chongqing, PR China

- Email: juyingjin@hotmail.com

- Contribution: This author helped with data collection

- Attestation: Juying Jin approved the final manuscript

- Conflict of interest: None

7. Author: Anthony M. Roche MB, ChB, FRCA

- Title: Associate Professor

- Affiliation: Department of Anesthesiology, Duke University Medical Center, Durham, NC

- Current Affiliation: Department of Anesthesiology, University of Washington, Seattle, WA.

- Email: aroche@uw.edu

- Contribution: This author helped with study design and conduct of the study

- Attestation: Anthony Roche approved the final manuscript

- Conflict of interest: Consultant for Deltex Medical and PATH

8. Author: Eric L. Eisenstein, DBA

- Title: Associate Professor

- Affiliation: Department of Medicine, Duke University Medical Center, Durham, NC

- Email: eric.eisenstein@dm.duke.edu

- Contribution: This author helped with data collection, data analysis and manuscript preparation

- Attestation: Eric Eisenstein approved the final manuscript

- Conflict of interest: None 
9. Author: Rex Edwards

- Title: Project Leader

- Affiliation: Duke Clinical Research Institute, Durham, NC

- Email: rex.edwards@duke.edu

- Contribution: This author helped with data collection and data analysis.

- Attestation: Rex Edwards approved the final manuscript

- Conflict of interest: None

10. Author: Kevin J. Anstrom, PhD

- Title: Associate Professor

- Affiliation: Department of Biostatistics and Bioinformatics, Duke University Medical Center, Durham, NC

- Email: kevin.anstrom@duke.edu

- Contribution: This author helped with data analysis and manuscript preparation

- Attestation: Kevin Anstrom approved the final manuscript

- Conflict of interest: None

11. Author: Richard E. Moon MD, CM, MSc, FRCP (C), FACP, FCCP

- Title: Professor

- Affiliation: Department of Anesthesiology, Duke University Medical Center, Durham, NC

- Email: richard.moon@dm.duke.edu

- Contribution: This author helped with study design and manuscript preparation

- Attestation: Richard Moon approved the final manuscript

- Conflict of interest: None

12. Author: Tong J. Gan, MD, MHS, FRCA, Li.Ac

- Title: Professor

- Affiliation: Department of Anesthesiology, Duke University Medical Center, Durham, NC

- Email: tong.gan@dm.duke.edu

- Contribution: This author helped with study design, conduct of the study, data collection, data analysis, and manuscript preparation

- Attestation: Tong J. Gan approved the final manuscript, attests to the integrity of the original data and the analysis reported in the manuscript

- Conflict of interest:

and the Enhanced Recovery Study Group

Enhanced Recovery Study Group

Elliott Bennett-Guererro MD, 
Catherine Kuhn MD,

Amy Manchester MD,

Grace McCarthy MD,

Eugene Moretti MD,

Andrew Peery MD,

Aaron Sandler MD,

Kerri Wahl MD,

Christopher Young MD.

Short title: Enhanced Recovery in Colorectal Surgery

Funding:

Department of Anesthesiology and Department of Surgery, Duke University Medical Center

\section{Corresponding Author:}

Tong J Gan, M.D., M.H.S., F.R.C.A.

Professor of Anesthesiology

Vice Chair for Clinical Research

Box 3094, Department of Anesthesiology,

Duke University Medical Center

Durham, NC 27710

Tel: 919-681-4660

Fax: 919-681-4698

tong.gan@duke.edu

IRB:

DUHS IRB Office

Hock Plaza

Suite 405

2424 Erwin Road

Campus Box 2712

Durham, NC 27705

Phone: (919) 668-5111

Fax: (919) 668-5125 


\section{Methods}

Data were collected from consecutive patients undergoing open or laparoscopic colorectal surgery during two time periods, before and after implementation of an ERAS protocol. Data collected included patient demographics, operative, and perioperative surgical and anesthesia data, need for analgesics, complications, inpatient medical costs, and 30-day readmission rates.

Results

There were 99 patients in the traditional care group, and 142 in the ERAS group. The median length of stay (LOS) was 5 days in the ERAS group compared with 7 days in the traditional group $(\mathrm{p}<0.001)$. The reduction in LOS was significant for both open procedures (median 6 days vs. 7 days, $\mathrm{p}=0.01$ ), and laparoscopic procedures ( 4 days vs. 6 days, $\mathrm{p}<0.0001$ ). ERAS patients had fewer urinary tract infections ( $13 \%$ vs. $24 \%, p=0.03)$. Re-admission rates were lower in ERAS patients (9.8\% vs. $20.2 \%, p=0.02)$ 


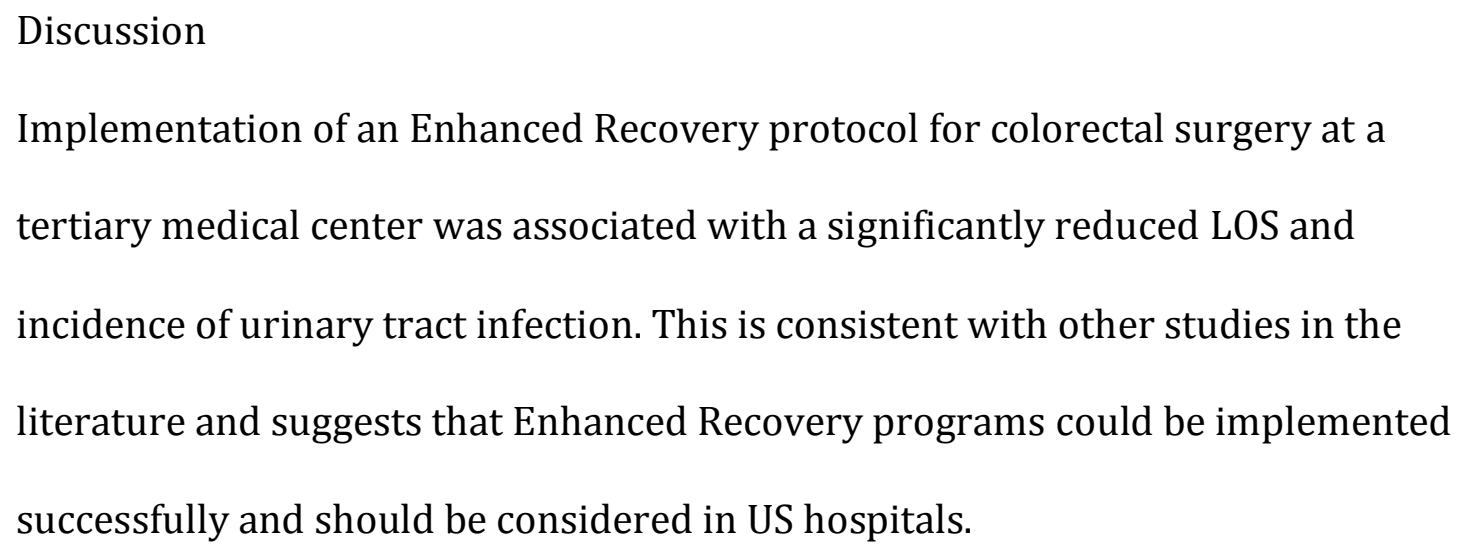




\section{Introduction}

Evidence-based medicine has been arguably the biggest driver for the change in practice and improvement in outcomes seen over the last twenty years, yet much routine perioperative care in colorectal surgery is not evidence-based. Despite lack of evidence for preoperative bowel preparation in colorectal surgery, routine use of nasogastric tubes, and nil by mouth instructions until bowel sounds are heard postoperatively, all three are still widely practiced.1-3

With traditional perioperative care, factors such as pain, stress, immobilization and postoperative ileus can lead to a length of stay (LOS) of greater than 10 days and complication rates of $45-48 \%$ after major elective open colorectal surgery. 4,5 If a complication occurs this has been shown to be a primary determinant of long-term survival. ${ }^{6}$ Khuri et al analyzed data from over 100,000 patients undergoing major surgery and demonstrated that the occurrence of any one of the 22 types of complications collected in the National Surgical Quality Improvement Program (NSQIP) database reduced median patient survival over the following 10 years by $69 \% .{ }^{6}$ Caring for patients with complications is also expensive, with the average cost of a surgical complication estimated at $\$ 10,000 .^{7}$

Enhanced Recovery After Surgery (ERAS) is a multidisciplinary perioperative care pathway that aims to standardize perioperative care, and apply evidence-based medicine to all aspects of a patient's operative journey. ${ }^{8}$ ERAS pathways also aim 
to reduce the stress response to surgery; and have been shown to reduce complications, and LOS after major surgery, with the added benefit of reducing healthcare costs. ${ }^{2,9,10}$

\begin{abstract}
Although Enhanced Recovery has been described for some time ${ }^{11}$, implementation is not widespread. There are many barriers to implementation that need to be overcome to achieve success. As a result, within the United States few major centers have reported adoption of an ERAS program. However, as we move toward a new era in the delivery of healthcare, a program that can improve quality yet reduce healthcare costs is of significant interest. The purpose of this study was to assess the clinical effectiveness and cost savings of an ERAS protocol for colorectal surgery at a tertiary medical center. We hypothesized that adoption of an ERAS protocol reduces length of hospital stay, complications, and medical costs when compared with traditional care.
\end{abstract}




\section{Methods}

After approval from Duke University Medical Center IRB (ref. no. Pro00028555, approved 2/16/2011), we compared data from consecutive patients undergoing open or laparoscopic colorectal surgery within the ERAS protocol with a previous cohort of patients before introduction of the ERAS protocol. Three colorectal surgeons at Duke University Medical Center performed all of the procedures.

\section{Study design}

We conducted a quantitative observational comparative effectiveness study. The study consisted of three phases.

1. Retrospective analysis of perioperative data from patients undergoing surgery according to traditional practices from January to June 2009. After this time practice changes gradually occurred in anticipation of implementation of the full ERAS protocol in 2010.

2. Implementation phase: the ERAS protocol was implemented in March 2010 after training of staff members. A three-month implementation period allowed all staff to become familiar with the protocol.

3. Post-implementation phase: between June and December 2010, perioperative data where collected prospectively from patients undergoing surgery within the ERAS protocol. 
Data collected included patient demographics, operative, and perioperative surgical and anesthesia data, need for analgesics, complications, inpatient medical costs, and 30-day readmission rates. All patients who underwent an elective colon or rectal resection by one of the three colorectal surgeons within the pre- and postimplementation periods were included in this analysis. There were significant differences in patient management before and after introduction of the ERAS protocol.

\section{Pre-Intervention Management}

Before introduction of the ERAS pathway, there was little standardization of care. Patients were fasted from midnight on the day of surgery, and all patients received bowel preparation. All other patient management was at the discretion of the surgical and anesthesia providers. Placement of thoracic epidurals was rare due to surgical preference for enoxaparin to be given 2 hours preoperatively (see RESULTS). Intraoperative fluid administration was based on changes in hemodynamics (BP and HR) and urine output. Early mobilization and feeding were not undertaken

\section{Post-implementation Management: ERAS protocol}

After implementation of the ERAS pathway, care was standardized using a pathway that was adapted from the evidence described in the ERAS consensus statement (Supplementary Tables 1 and 2). ${ }^{2}$ Patients in the ERAS group were educated in the preoperative surgical clinic about the ERAS pathway and were encouraged to ask 
questions. Routine bowel preparation was not performed for colonic procedures, and patients were allowed to drink clear fluids until 3 hours preoperatively. Patients also were given $240 \mathrm{~mL}$ of an oral preoperative drink (Gatorade ${ }^{\mathrm{TM}}$, PepsiCo, Purchase, NY), which they were told to drink 3 hours preoperatively.

In all patients without contraindications an epidural catheter was placed at the T8T10 level, while in the preoperative holding area. Small doses of midazolam and fentanyl were given to facilitate epidural insertion and maintain patient comfort. After placement of the epidural and before skin incision patients received thromboprophylaxis with heparin 5000 i.u. subcutaneously, and perioperative antibiotics were administered before surgical incision.

\begin{abstract}
All patients received general anesthesia with an oral endotracheal tube. Intraoperative analgesia was provided using a single epidural dose of hydromorphone at induction (0.4-0.8 mg based on body weight) followed by an infusion of bupivacaine $(2.5 \mathrm{mg} / \mathrm{mL}$ at $3-6 \mathrm{~mL} / \mathrm{h})$. No intraoperative intravenous opioids were given after induction of anesthesia without discussion with the attending anesthesiologist.
\end{abstract}

Intravenous (IV) crystalloid (Lactated Ringers) $1 \mathrm{~L}$ was given during induction of anesthesia. An infusion of Lactated Ringers was then started and maintained throughout the procedure using a dedicated infusion pump (set at $3 \mathrm{~mL} / \mathrm{kg} / \mathrm{h}$ for laparoscopic colectomy, and $5 \mathrm{~mL} / \mathrm{kg} / \mathrm{h}$ for open colectomy, based on lean body 
weight). All patients received intraoperative Goal-Directed Fluid Therapy (GDFT) with a minimally invasive cardiac output monitor. Boluses of IV colloid were given to optimize stroke volume (SV) using a 10\% algorithm (see Supplementary Table 2). The monitor used was normally the Esophageal Doppler (EDM ${ }^{\mathrm{TM}}$ Deltex Medical, Inc., Irving, TX ). The LiDCORapid ${ }^{\mathrm{TM}}$ (LiDCO Ltd., Cambridge, UK) was used as an alternative when invasive blood pressure monitoring was performed. The need for an arterial line was based on the clinical judgment of the anesthesiologist.

Orogastric tubes, placed following the induction of anesthesia, were removed at the end of the procedure. Surgical drains were not routinely used.

Postoperatively patient's urinary catheter was removed on the day after surgery. Postoperative analgesia was provided using an epidural local anesthetic/opioid infusion (bupivacaine $0.125 \%$ and hydromorphone $10 \mathrm{mcg} / \mathrm{mL}$ ) for up to 72 hours. Regular adjunctive analgesia with acetaminophen and NSAIDS was used whenever possible, and patients were transitioned to oral opioids after removal of the epidural catheter. Patients were encouraged to drink liquids immediately after surgery. IV fluid administration was discontinued once adequate oral intake was achieved, usually on the first morning after surgery. All preoperative medications were recommenced when patients tolerated oral intake.

Patients were cared for in an environment that encouraged early mobilization. They were encouraged to be out of bed on the day of surgery, and for at least six hours on every subsequent day. 


\section{Cost Analysis}

Patient bills for the index hospitalization period were obtained from the Duke University Medical Center (DUMC) patient data repository. Medical costs were estimated by multiplying hospital department charges on study subject bills by their associated ratios of cost to charge from DUMC's Medicare Cost Reports. For reporting purposes, Medicare Cost Report departments were aggregated into clinically meaningful units. Results are presented as unadjusted mean values by treatment strategy with estimated differences and 95\% confidence intervals before and after adjusting for age, sex, and procedure type. Unadjusted and adjusted nonparametric bootstrap analyses were used to estimate the variability of cost estimates and to develop a cost acceptability curve that showed the percent of bootstrap samples for which use of the ERAS protocol would be cost saving versus the traditional protocol. ${ }^{12,13}$

\section{Statistical Analysis}

A sample size analysis showed that a Mann-Whitney rank-sum test based on a symmetric distribution with expected mean difference of 2 days in LOS and a standard deviation of 5 would have $80 \%$ power with 106 patients per group. If the group distributions of LOS are skewed, 100 patients per group provides $95 \%$ power assuming a $65 \%$ probability of a shorter LOS in the ERAS group. All relevant patient characteristics, operative and postoperative data were summarized with descriptive statistics and compared between the pre- and post- implementation groups with t-tests, rank-sum tests, or chi-squared tests as appropriate. The 
primary clinical outcome was postoperative hospital LOS. LOS was defined as postoperative number of nights in the hospital. Secondary outcomes were days to first stool, estimated blood loss, postoperative pain scores (measured twice a day), postoperative IV morphine equivalents ${ }^{14}$, surgical site infection (SSI, includes superficial incisional infection, deep incisional infection, organ space infection and wound disruption), urinary tract infusion (UTI), readmission rate, and death. Pain was assessed using a 0-10 verbal response scale (VRS), where "0" represents no pain and " 10 " represents worst possible pain twice a day as part of the standard of care nursing protocol. The highest pain reported each day was recorded from the day of surgery until discharge or the fifth day post-op. Then the set of maximum pain scores were averaged for each patient to give each patient an average maximum pain score. Pain scores were compared between therapy groups using a rank-sum test. SSI and UTI were diagnosed according to criteria from the American College Of Surgeons National Surgical Quality Improvement Program. ${ }^{15}$

Because of its skewed distribution, LOS was initially compared between groups with an unadjusted rank-sum test. For covariable-adjusted testing, a parametric multivariable regression tested the effect of ERAS on a log-transformation of LOS, adjusting for surgical approach (laparoscopic or open) and patient characteristics including ASA class, age, gender, BMI, surgical duration, and pelvic procedure. The interactions of effects of ERAS and all these co-variables were also tested. Because a laparoscopic approach has a significant effect on LOS, and was also more frequent after ERAS implementation, special attention was given to distinguishing between 
these two effects. The interaction was tested in the multivariable model, and as a follow-up the ERAS effect was tested in open and laparoscopic groups separately, both with unadjusted rank sum tests and with multivariable regression. The log transformation of LOS did not attain Kolmogorov-Smirnoff test standards for normality, but it greatly reduced the test statistics as well as skewness and kurtosis. These indicators, along with the consistency between the rank-sum test and a t-test with the log-transformed values, gave us confidence that the distribution was not unduly influencing the results of the parametric adjusted regression. All secondary clinical outcomes were compared with t-tests, rank-sum tests, or chi-square tests without co-variable adjustment. All comparisons were made at a significance level of 0.05 , and all analyses were performed with $\mathrm{SAS} \circledast$ version 9.3 (SAS Institute, Cary, NC). 


\section{Results}

There were 99 patients in the traditional care group, and 142 in the ERAS group.

The relevant patient characteristics and surgical details are included in Table 1.

There was no significant difference in age, sex, BMI, or ASA status between the two groups. Operations did not differ statistically in terms of length of surgery (median $300 \mathrm{~min}$ in the traditional group and $270 \mathrm{~min}$ in the ERAS group, $\mathrm{p}=0.11$ ), however significantly more patients in the ERAS group underwent a laparoscopic rather than an open surgical approach $(56.3 \%$ vs. $40.4 \%, \mathrm{p}=0.01)$.

The median LOS was 5 days (interquartile range $(I Q R)=3-7)$ in the ERAS group compared with 7 days (IQR $=5-8$ ) in the traditional group. The p-values for the effect of ERAS on LOS were $\mathrm{p}<0.0001$ in both the unadjusted rank-sum test and in the adjusted covariate model. The reduction in median LOS was significant for open procedures ( 6 days vs. 7 days, $p=0.01$ ), and laparoscopic procedures ( 4 days vs. 6 days, $\mathrm{p}<0.0001$, rank-sum tests) (Table 2). While surgical approach had a significant effect on LOS ( $p<0.0001$ in both the unadjusted rank-sum test and in the adjusted covariate model), the effect of ERAS was statistically consistent regardless of approach. That is, in the model adjusting for approach and other covariables, the interaction between ERAS and approach was non-significant $(p=0.5398$, Table $2 b)$. In addition to surgical approach, the other significant covariables in our model were female gender (shorter stay, $\mathrm{p}=0.0016$ ) and shorter duration of surgery (shorter stay, $\mathrm{p}=0.0032$ ). There was also a significant reduction 
in re-admission rates within 30 days in ERAS patients compared to patients in the traditional group ( $9.8 \%$ vs. $20.2 \%$, unadjusted chi-square $p=0.02)$.

Thoracic epidural analgesia (TEA) was used in $92 \%$ of patients in the ERAS group compared to $18 \%$ of patients in the traditional group $(\mathrm{p}<0.0001)$. This resulted in a significant reduction in the intraoperative and postoperative morphine requirements in the ERAS patients compared to the traditional group (Table 3). Pain scores were significantly lower in the ERAS group compared to controls (Table 3).

GDFT was used in all patients in the ERAS group. ERAS patients received less crystalloid (mean $2261 \mathrm{~mL}$ vs. $3170 \mathrm{~mL}$, p<0.0001) and more colloid (mean $1072 \mathrm{~mL}$ vs. $716 \mathrm{~mL}, \mathrm{p}<0.0001)$ than patients in the traditional group, resulting in an overall reduction in the amount of intraoperative IV fluid administered in ERAS patients. There was no significant difference in intraoperative urine output between the two groups.

In the ERAS group, 74\% (105/142) of patients began clear fluids on the day of surgery, compared to $15 \%(15 / 99)$ in the traditional group ( $\mathrm{p}<0.0001)$. Early mobilization was accomplished in 70\% (99/142) of patients in the ERAS group ambulating on postoperative day (POD) 1 . There was a significant reduction in the duration of ileus in the ERAS patients compared with traditional care (mean time to first stool 2.4 days vs. 3.4 days, $\mathrm{p}=0.0001$ ). 
There was a significant reduction in urinary tract infection in ERAS patients $(13 \%$ vs. $24 \%, p=0.03$ ), presumably related to the earlier removal of Foley catheters. There was a lower percentage of surgical site infection $(28 \%$ vs. $37 \% \mathrm{p}=0.15)$ in ERAS patients that did not reach statistical significance.

\begin{abstract}
Patients undergoing laparoscopic surgery in the traditional group received more opioids and experienced more pain (Table 4). Intraoperative and postoperative opioid use, the average postoperative pain score, and the highest postoperative pain score, were all significantly reduced in the ERAS group.
\end{abstract}

Overall there was no statistically significant difference in unadjusted total medical costs for patients in the ERAS pathway and traditional care groups $(\$ 18,377 \mathrm{vs}$. $\$ 20,537$; difference, $-\$ 2161 ; 95 \% \mathrm{CI},-\$ 6352$ to $\$ 2030 ; \mathrm{p}=0.31$ ) (Table 5A). Similar results for the ERAS pathway versus traditional care were observed after adjustment for age, sex, and procedure type (difference, $-\$ 1854 ; 95 \% \mathrm{CI}$, $-\$ 6072$ to $\$ 2363 ; p=0.39$ ) (Table 5B). While the use of open surgery was more costly than laparoscopic surgery, this difference also was not significant after adjustment (difference, $\$ 2849 ; 95 \% \mathrm{CI}$, $\$ 1315$ to $\$ 7012 ; \mathrm{p}=0.18$ ). Use of the ERAS protocol was associated with reductions in room-related costs and an increase in medical and surgical supply costs before and after adjustment. 
The net reduction in medical costs achieved with the ERAS protocol was approximately $10 \%$ of traditional care medical costs before and after adjustment. These results were confirmed in bootstrap analyses in which use of the ERAS pathway versus traditional care would be expected to achieve some degree of cost saving in $85 \%$ of unadjusted and $82 \%$ of adjusted medical cost samples (Figures 1 and 2). 


\title{
Discussion
}

Implementation of an Enhanced Recovery protocol for colorectal surgery at a tertiary medical center was associated with a significantly reduced LOS, incidence of urinary tract infection, and readmission rates. The reduction in LOS was similar to other studies in the literature from diverse centers around the world in open colorectal surgery. ${ }^{4,5,16}$

\author{
For patients without complications, LOS is largely determined by the duration of \\ postoperative ileus. Once the ileus has resolved most patients are discharged home \\ within 1-2 days. Several perioperative factors including preoperative fasting and \\ bowel preparation, analgesic and anesthetic techniques, and perioperative fluid \\ management influence the duration of ileus. ${ }^{17}$ Enhanced recovery programs aim to \\ minimize ileus to facilitate immediate feeding and mobilization on the day of \\ surgery.
}

Our study showed a greater reduction in LOS for laparoscopic surgery than for open surgery. This was surprising and could possibly be due to the fact that there was a greater change in practice from baseline in the laparoscopic procedures. Only $7.5 \%$ of patients undergoing laparoscopic surgery in the traditional group received epidural anesthesia compared to $92.5 \%$ in the ERAS group. This resulted in a large reduction in opioid use and pain scores in patients undergoing laparoscopic colectomy within the ERAS program. 
Compared with traditional care the re-admission rate was also reduced in patients following the ERAS protocol, demonstrating that patients were physiologically ready to leave hospital earlier with the ERAS pathway.

The ERAS pathway can be divided into three components - preoperative, intraoperative, and postoperative. The key principals of the preoperative component are to prepare the patient (and the relatives) psychologically for the care program, managing expectation and to prevent a prolonged fasting state. This is achieved through a combination of nutritional supplements, the avoidance of routine bowel preparation, allowing clear fluids until 2 hours before induction of anesthesia, and use of a preoperative carbohydrate drink. These interventions are evidence-based, and improve subjective well-being, primarily by reducing thirst. ${ }^{18}$

Intraoperative elements are the key to successful ERAS pathways, and lay the groundwork to enable early mobilization and feeding. Minimally invasive surgery is an important component. 8,19 The two major anesthetic factors are fluid management optimization and the minimization of intravenous opioids, which can delay the return of normal bowel function. ${ }^{20}$

The first goal of intraoperative fluid management should be avoidance of fluid excess, which has shown to be associated with adverse outcomes. ${ }^{21,22}$ The amount of intraoperative crystalloid given in our study was significantly reduced compared to similar surgeries ten years ago when it was not unusual to receive greater than 6 
liters of intraoperative crystalloid. ${ }^{23,24}$ Only $20 \%$ of an intravenous crystalloid bolus remains in the circulation after 1 hour, ${ }^{25}$ with the rest distributed in the extravascular space and contributing to perioperative weight gain, bowel wall edema, and prolonged ileus. ${ }^{21}$ In a recent analysis of the different elements of an ERAS protocol, avoidance of fluid excess was the single most important factor. ${ }^{26}$ In addition, GDFT with a minimally invasive cardiac output monitor can optimize stroke volume. Multiple studies have shown that GDFT reduces hospital LOS and complications after major surgery. ${ }^{27}$ These two goals of fluid therapy are not mutually exclusive and can be achieved with a background crystalloid infusion supplemented by colloid boluses to maximize stroke volume. However, there is currently a lack of information on the role of GDFT within an ERAS program.

Thoracic epidural anesthesia is well established as the analgesic technique of choice in open major abdominal surgery, with studies showing consistently superior analgesia to intravenous opioids in the first 72 hours after surgery. ${ }^{28}$ TEA is also highly effective at reducing postoperative ileus compared to intravenous opioids, with a reduction in the duration of ileus after open colectomy of approximately 36 hours. ${ }^{20}$

The choice of analgesic technique for laparoscopic surgery is more controversial, and many centers use alternative multimodal regimes incorporating transversus abdominis plane (TAP) blocks ${ }^{29}$ or spinal anesthesia. ${ }^{30}$ We chose to administer epidural anesthesia for all patients in our ERAS program, including those 
undergoing laparoscopic surgery, because our institution is a tertiary referral center where a significant proportion of the laparoscopic procedures are complex operations involving rectal resection, pouch formation, inflammatory bowel disease patients, or redo operations. In our patient population, patients undergoing laparoscopic surgery seemed to benefit from epidural analgesia with a dramatic reduction in pain scores and postoperative opioid use that was as significant for laparoscopic surgery as open procedures.

Other centers have shown that epidurals can impair discharge after laparoscopic colectomy by reducing mobility and complicating fluid management. ${ }^{30}$ Why is this so different to our results? Different patient populations may play a role and certainly laparoscopic surgeries cannot all be considered equal. Very few of our patients had simple colectomies without rectal work or stoma formation, where discharge can often be achieved within 2-3 days, and therefore epidural analgesia may not be beneficial. Further studies are needed to evaluate different regional techniques in different types of laparoscopic colorectal surgery.

Successful implementation of the preoperative and intraoperative elements of an ERAS pathway enables mobilization and feeding to occur on the day of surgery. Patients are encouraged to sit out of bed for at least 6 hours on every postoperative day; and with only evidence-based use of surgical drains, catheters, or nasogastric tubes. $^{31}$. 
The percentage of patients having a surgical site infection (SSI) in our study was high. SSIs are the most common complication after colorectal surgery, and although some centers have reported SSI rates less than $10 \%,{ }^{32}$ the incidence of SSIs after colorectal surgery has been reported to be as great as $25-30 \%$ in several large, observational studies. ${ }^{33-35}$ Our SSI rate decreased after introduction of the ERAS program but remains high and we are currently evaluating a bundle of care measures to reduce bacterial contamination of the surgical site. Future strategies should also concentrate on timely recognition and management of complications when they occur, which is an important determinant of postoperative mortality. ${ }^{36,37}$

There was a trend towards lower medical costs in the ERAS group that did not reach statistical significance. However, cost data typically are skewed and require a larger sample than was available in the present study to detect significant differences. Therefore bootstrap analysis was used to look at the distribution of the difference in mean values of the two samples, and showed that the ERAS protocol would be expected to cost less than control in $85 \%$ of unadjusted and $82 \%$ of adjusted medical cost samples. This was mainly related to the reduction in LOS in the ERAS group.

The main limitation of our study is that it was not a blinded randomized controlled trial (RCT). Furthermore, all of the elements of the ERAS protocol were introduced simultaneously. Thus, it is impossible to determine which elements may be 
responsible for the observed outcome differences. Unfortunately, it is practically impossible to blind a bundle of care with so many different interventions. Additionally the complexity in implementing ERAS programs would make a randomized controlled trial (RCT) to assess their clinical effectiveness technically challenging. Implementation programs can take several months and involves education and training for all perioperative care providers. It is therefore difficult and may indeed be confusing and potentially unsafe for patients to be randomized to traditional or ERAS care as would occur in a RCT. However, in our study there were no significant differences in the baseline characteristics between the patients during the control and the intervention periods, and the magnitude of the change in LOS was substantial.

\author{
Another limitation is that non-clinical confounders, such as the availability of the \\ surgical team to make discharge decisions can affect the time of discharge from \\ hospital. Whilst no practice changes occurred in discharge planning during the \\ study the change in organizational workflows after the introduction of the ERAS \\ pathway may have improved the discharge process in the ERAS group compared to \\ the traditional group.
}

It is possible that the observed benefits could be due to a laparoscopic approach and the use of epidural analgesia. It is also possible that it is not the epidural per se that causes the observed benefits but the early feeding and mobilization that the epidural facilitated. In other words, if the patient undergoing traditional care has a 
good working epidural but is still fasted and undergoing bed rest, the benefits of the epidural in aiding recovery may not be realized.

Finally, it is also possible that all elements of the protocol are important with the reduction in LOS and complications proportional to the number of elements implemented. ${ }^{26}$ As the enhanced recovery process develops, further research will aim to identify crucial elements of the protocol. Some interventions may turn out to be more important than others, and some may be nonessential. However, current evidence suggests that adherence to the ERAS protocol as a whole is the best approach. ${ }^{26}$

In conclusion, we showed a significant reduction in LOS after implementation of an enhanced recovery program for colorectal surgery. The reduction in LOS was significant for patients undergoing open and laparoscopic colorectal resection. Our data support the evidence that enhanced recovery programs should be considered as the new standard of care for patients undergoing elective colorectal resection. 


\section{References}

1. Gustafsson UO, Scott MJ, Schwenk W, Demartines N, Roulin D, Francis N, McNaught CE, MacFie J, Liberman AS, Soop M, Hill A, Kennedy RH, Lobo DN, Fearon K, Ljungqvist O. Guidelines for perioperative care in elective colonic surgery: Enhanced Recovery After Surgery (ERAS(R)) Society recommendations. Clin Nutr 2012;31:783-800.

2. Lassen K, Soop M, Nygren J, Cox PB, Hendry PO, Spies C, von Meyenfeldt MF, Fearon KC, Revhaug A, Norderval S, Ljungqvist O, Lobo DN, Dejong CH. Consensus review of optimal perioperative care in colorectal surgery: Enhanced Recovery After Surgery (ERAS) Group recommendations. Arch Surg 2009;144:961-9.

3. Nygren J, Thacker J, Carli F, Fearon KC, Norderval S, Lobo DN, Ljungqvist O, Soop M, Ramirez J. Guidelines for perioperative care in elective rectal/pelvic surgery: Enhanced Recovery After Surgery (ERAS(R)) Society recommendations. Clin Nutr 2012;31:801-16.

4. Muller S, Zalunardo MP, Hubner M, Clavien PA, Demartines N. A fast-track program reduces complications and length of hospital stay after open colonic surgery. Gastroenterology 2009;136:842-7.

5. Serclova Z, Dytrych P, Marvan J, Nova K, Hankeova Z, Ryska O, Slegrova Z, Buresova L, Travnikova L, Antos F. Fast-track in open intestinal surgery: prospective randomized study (Clinical Trials Gov Identifier no. NCT00123456). Clin Nutr 2009;28:618-24. 
6. Khuri SF, Henderson WG, DePalma RG, Mosca C, Healey NA, Kumbhani DJ. Determinants of long-term survival after major surgery and the adverse effect of postoperative complications. Ann Surg 2005;242:326-41; discussion 41-3.

7. Birkmeyer JD, Gust C, Dimick JB, Birkmeyer NJ, Skinner JS. Hospital quality and the cost of inpatient surgery in the United States. Ann Surg 2012;255:15.

8. Kehlet H, Wilmore DW. Evidence-based surgical care and the evolution of fast-track surgery. Ann Surg 2008;248:189-98.

9. Varadhan KK, Neal KR, Dejong CH, Fearon KC, Ljungqvist O, Lobo DN. The enhanced recovery after surgery (ERAS) pathway for patients undergoing major elective open colorectal surgery: a meta-analysis of randomized controlled trials. Clin Nutr 2010;29:434-40.

10. Kehlet H, Wilmore DW. Multimodal strategies to improve surgical outcome. Am J Surg 2002;183:630-41.

11. Kehlet H. Multimodal approach to control postoperative pathophysiology and rehabilitation. Br J Anaesth 1997;78:606-17.

12. Barber JA, Thompson SG. Analysis of cost data in randomized trials: an application of the non-parametric bootstrap. Stat Med 2000;19:3219-36.

13. Thompson SG, Barber JA. How should cost data in pragmatic randomised trials be analysed? BMJ 2000;320:1197-200. 
14. U. S. Department of Health and Human Services. Management of cancer pain: adults. Rockville (MD): Agency for Health Care Policy and Research; 1994 AHCPR Pub. No. 94-0593

15. National Surgical Quality Improvement Project - classic variables and definitions.

http://nsqip.healthsoftonline.com/lib/Documents/Ch 4 Variables Definitio ns 062810.pdf.

16. Khoo CK, Vickery CJ, Forsyth N, Vinall NS, Eyre-Brook IA. A prospective randomized controlled trial of multimodal perioperative management protocol in patients undergoing elective colorectal resection for cancer. Ann Surg 2007;245:867-72.

17. Kehlet H. Postoperative ileus--an update on preventive techniques. Nat Clin Pract Gastroenterol Hepatol 2008;5:552-8.

18. Ljungqvist O, Soreide E. Preoperative fasting. Br J Surg 2003;90:400-6.

19. Adamina M, Kehlet H, Tomlinson GA, Senagore AJ, Delaney CP. Enhanced recovery pathways optimize health outcomes and resource utilization: a meta-analysis of randomized controlled trials in colorectal surgery. Surgery 2011;149:830-40.

20. Marret E, Remy C, Bonnet F. Meta-analysis of epidural analgesia versus parenteral opioid analgesia after colorectal surgery. Br J Surg 2007;94:66573.

21. Brandstrup B, Tonnesen H, Beier-Holgersen R, Hjortso E, Ording H, LindorffLarsen K, Rasmussen MS, Lanng C, Wallin L, Iversen LH, Gramkow CS, 
Okholm M, Blemmer T, Svendsen PE, Rottensten HH, Thage B, Riis J, Jeppesen IS, Teilum D, Christensen AM, Graungaard B, Pott F. Effects of intravenous fluid restriction on postoperative complications: comparison of two perioperative fluid regimens: a randomized assessor-blinded multicenter trial. Ann Surg 2003;238:641-8.

22. Chappell D, Jacob M, Hofmann-Kiefer K, Conzen P, Rehm M. A rational approach to perioperative fluid management. Anesthesiology 2008;109:723-40.

23. Moretti EW, Robertson KM, El-Moalem H, Gan TJ. Intraoperative colloid administration reduces postoperative nausea and vomiting and improves postoperative outcomes compared with crystalloid administration. Anesth Analg 2003;96:611-7, table of contents.

24. Gan TJ, Soppitt A, Maroof M, el-Moalem H, Robertson KM, Moretti E, Dwane P, Glass PS. Goal-directed intraoperative fluid administration reduces length of hospital stay after major surgery. Anesthesiology 2002;97:820-6.

25. Awad S, Dharmavaram S, Wearn CS, Dube MG, Lobo DN. Effects of an intraoperative infusion of $4 \%$ succinylated gelatine (Gelofusine(R)) and 6\% hydroxyethyl starch (Voluven(R)) on blood volume. Br J Anaesth 2012;109:168-76.

26. Gustafsson UO, Hausel J, Thorell A, Ljungqvist O, Soop M, Nygren J. Adherence to the enhanced recovery after surgery protocol and outcomes after colorectal cancer surgery. Arch Surg 2011;146:571-7. 
27. Hamilton MA, Cecconi M, Rhodes A. A systematic review and meta-analysis on the use of preemptive hemodynamic intervention to improve postoperative outcomes in moderate and high-risk surgical patients. Anesth Analg 2011;112:1392-402.

28. Werawatganon T, Charuluxanun S. Patient controlled intravenous opioid analgesia versus continuous epidural analgesia for pain after intraabdominal surgery. Cochrane Database Syst Rev 2005:CD004088.

29. Johns N, O'Neill S, Ventham N, Barron F, Brady R, Daniel T. Clinical effectiveness of transversus abdominis plane (TAP) block in abdominal surgery: a systematic review and meta-analysis. Colorectal Dis 2012.

30. Levy BF, Scott MJ, Fawcett W, Fry C, Rockall TA. Randomized clinical trial of epidural, spinal or patient-controlled analgesia for patients undergoing laparoscopic colorectal surgery. Br J Surg 2011;98:1068-78.

31. Gustafsson UO, Scott MJ, Schwenk W, Demartines N, Roulin D, Francis N, McNaught CE, Macfie J, Liberman AS, Soop M, Hill A, Kennedy RH, Lobo DN, Fearon K, Ljungqvist O. Guidelines for Perioperative Care in Elective Colonic Surgery: Enhanced Recovery After Surgery (ERAS) Society Recommendations. World J Surg 2012.

32. Cannon JA, Altom LK, Deierhoi RJ, Morris M, Richman JS, Vick CC, Itani KM, Hawn MT. Preoperative oral antibiotics reduce surgical site infection following elective colorectal resections. Dis Colon Rectum 2012;55:1160-6. 
33. Itani KM, Wilson SE, Awad SS, Jensen EH, Finn TS, Abramson MA. Ertapenem versus cefotetan prophylaxis in elective colorectal surgery. N Engl J Med 2006;355:2640-51.

34. Smith RL, Bohl JK, McElearney ST, Friel CM, Barclay MM, Sawyer RG, Foley EF. Wound infection after elective colorectal resection. Ann Surg 2004;239:599-605; discussion -7.

35. Wick EC, Hobson DB, Bennett JL, Demski R, Maragakis L, Gearhart SL, Efron J, Berenholtz SM, Makary MA. Implementation of a surgical comprehensive unit-based safety program to reduce surgical site infections. J Am Coll Surg 2012;215:193-200.

36. Ghaferi AA, Birkmeyer JD, Dimick JB. Complications, failure to rescue, and mortality with major inpatient surgery in medicare patients. Ann Surg 2009;250:1029-34.

37. Ghaferi AA, Birkmeyer JD, Dimick JB. Variation in hospital mortality associated with inpatient surgery. N Engl J Med 2009;361:1368-75. 
Table 1. Patient demographics, anthropometrics, and clinical characteristics

\begin{tabular}{|c|c|c|c|}
\hline & $\begin{array}{c}\text { Traditional } \\
\text { N=99 }\end{array}$ & $\begin{array}{c}\text { ERAS } \\
\mathrm{N}=142\end{array}$ & P-Value \\
\hline Age (year) & $56 \pm 15$ & $58 \pm 15$ & 0.54 \\
\hline Male/female & $43 / 56$ & $69 / 73$ & 0.43 \\
\hline Height (cm) & $171 \pm 10$ & $172 \pm 10$ & 0.41 \\
\hline Weight (Kg) & $81 \pm 20$ & $83 \pm 20$ & 0.47 \\
\hline BMI & $27.7 \pm 5$ & $28.5 \pm 7$ & 0.78 \\
\hline $\begin{array}{l}\text { ASA Physical Status } \\
\text { I } \\
\text { II } \\
\text { III } \\
\text { IV }\end{array}$ & $\begin{array}{c}3 \\
39 \\
53 \\
4\end{array}$ & $\begin{array}{c}0 \\
53 \\
87 \\
2\end{array}$ & 0.0715 \\
\hline $\begin{array}{l}\text { Type of surgery } \\
\text { Colon } \\
\text { Pelvic }\end{array}$ & $\begin{array}{l}54(55 \%) \\
45(45 \%)\end{array}$ & $\begin{array}{l}75(53 \%) \\
67(47 \%)\end{array}$ & 0.79 \\
\hline $\begin{array}{l}\text { Laparoscopic approach } \\
\text { (\%) }\end{array}$ & $40.4 \%$ & $56.3 \%$ & 0.01 \\
\hline $\begin{array}{l}\text { Duration of surgery } \\
\text { (min)* }\end{array}$ & $300 \pm 136$ & $270 \pm 126$ & 0.11 \\
\hline
\end{tabular}

Data are expressed as mean \pm SD or $\mathrm{n}(\%)$

* Incision to end of surgery 
Table 2a. Length of stay

\begin{tabular}{|l|c|c|c|c|c|c|}
\hline & \multicolumn{2}{|c|}{ Mean \pm SD } & \multicolumn{2}{c|}{ Median (IQR) } & & \\
\hline & Traditional & ERAS & Traditional & ERAS & $\begin{array}{c}\text { Diff } \\
\text { (95\% CI)* }\end{array}$ & $\begin{array}{c}\text { P- } \\
\text { Value** }\end{array}$ \\
\hline $\begin{array}{l}\text { All procedures } \\
\text { (days) }\end{array}$ & $8.3 \pm 8.1$ & $6 \pm 4.2$ & $7(5,8)$ & $5(3,7)$ & $2(1-2)$ & $<0.0001$ \\
\hline $\begin{array}{l}\text { Open procedures } \\
\text { (days) }\end{array}$ & $9.3 \pm 6.6$ & $7.1 \pm 3.9$ & $7(6,9)$ & $6(5,8)$ & $1(0-2)$ & 0.0133 \\
\hline $\begin{array}{l}\text { Laparoscopic } \\
\text { procedures (days) }\end{array}$ & $6.9 \pm 5$ & $5.2 \pm 4.2$ & $6(4.5,7.5)$ & $4(3,5.5)$ & $2(1-2)$ & $<0.0001$ \\
\hline
\end{tabular}

* Difference between medians, and estimated 95\% Confidence limits for the difference.

** $\mathbf{P}$-values in this table are from unadjusted rank-sum tests comparing therapy groups. 
Table 2b. Multivariable linear regression on log-transformed LOS

\begin{tabular}{|c|c|c|}
\hline Factor & $\begin{array}{c}\text { Beta } \\
\text { Coefficient }\end{array}$ & P-Value \\
\hline $\begin{array}{c}\text { Laparoscopic } \\
\text { approach }\end{array}$ & -0.218 & 0.0001 \\
\hline ERAS protocol & -0.253 & $<0.0001$ \\
\hline ASA 3-4 & 0.128 & 0.0516 \\
\hline $\begin{array}{c}\text { Duration of } \\
\text { surgery } \\
\text { (minutes) }\end{array}$ & 0.0007 & 0.0033 \\
\hline $\begin{array}{c}\text { Female gender } \\
\text { Interaction: }\end{array}$ & -0.200 & 0.0019 \\
$\begin{array}{c}\text { Laparoscopic } \\
\text { surgery and } \\
\text { ERAS protocol }\end{array}$ & -0.080 & 0.5398 \\
\hline
\end{tabular}

Duration of surgery is the number of minutes from incision to end of surgery. No transformation of this number was necessary, as none provided meaningful improvement in the correlation with $\log (\mathrm{LOS})$ 
Table 3: Patient Outcomes

\begin{tabular}{|l|c|c|c|}
\hline & Traditional & ERAS & P-Value \\
\hline POD to first oral liquid & $1.8 \pm 1.9$ & $0.5 \pm 1$ & $<0.0001$ \\
\hline POD to first stool & $3.4 \pm 1.7$ & $2.4 \pm 1.6$ & 0.0001 \\
\hline OR crystalloid & $3170 \pm 1621$ & $2261 \pm 1282$ & $<0.0001$ \\
\hline OR colloid & $716 \pm 519$ & $1072 \pm 530$ & $<0.0001$ \\
\hline OR blood & $83 \pm 321$ & $80 \pm 474$ & 0.142 \\
\hline OR FFP & $20 \pm 128$ & $33 \pm 209$ & 0.9408 \\
\hline OR estimated blood loss & $319 \pm 314$ & $246 \pm 430$ & 0.0003 \\
\hline OR urine output & $460 \pm 349$ & $490 \pm 318$ & 0.2799 \\
\hline $\begin{array}{l}\text { Highest postoperative pain } \\
\text { score }\end{array}$ & $6.8 \pm 2.3$ & $5.6 \pm 2.7$ & 0.0004 \\
\hline $\begin{array}{l}\text { Average pain score } \\
\text { Days 0-5 }\end{array}$ & $4.9 \pm 2.1$ & $3.3 \pm 1.9$ & $<0.0001$ \\
\hline $\begin{array}{l}\text { Total intraoperative } \\
\text { morphine equivalents (mg) }\end{array}$ & $53.1 \pm 28$ & $20.8 \pm 23.5$ & $<0.0001$ \\
\hline $\begin{array}{l}\text { Total postoperative } \\
\text { morphine equivalents (mg) } \\
\text { Median (IQR) } \\
\text { Mean }\end{array}$ & $120(69-267)$ & $29.8(10-85)$ & $<0.0001$ \\
\hline Surgical Site Infection (\%) & $196 \pm 191$ & $85 \pm 175$ & 0.16 \\
\hline Urinary Tract Infection (\%) & $24.3 \%$ & $28.8 \%$ & 0.03 \\
\hline Readmission (\%) & $20.2 \%$ & $13.4 \%$ & 0.02 \\
\hline Death (\%) & $1 \%$ & $0 \%$ & 0.41 \\
\hline \multicolumn{2}{|l|}{} \\
\hline
\end{tabular}

$\mathrm{POD}=$ Postoperative day; $\mathrm{OR}=0$ perating room 
Table 4: Pain scores and opioid consumption by surgical approach

\begin{tabular}{|c|c|c|c|c|c|c|}
\hline & \multicolumn{2}{|c|}{ Median (IQR) } & \multicolumn{2}{|c|}{ Mean \pm SD } & \multirow[b]{2}{*}{ P-Value } \\
\hline & & Traditional & ERAS & Traditional & ERAS & \\
\hline \multirow{2}{*}{$\begin{array}{c}\text { Highest } \\
\text { postoperative } \\
\text { pain score }\end{array}$} & Open & $7(5,9)$ & $6.5(5,8)$ & $6.6 \pm 1.7$ & $6.3 \pm 2.3$ & 0.36 \\
\hline & Lap & $7.5(6,8)$ & $5(3,7)$ & $7.1 \pm 1.8$ & $5 \pm 2.9$ & $<0.0001$ \\
\hline \multirow{2}{*}{$\begin{array}{l}\text { Average pain } \\
\text { score Days 0-5 }\end{array}$} & Open & $4.5(3.4,6.5)$ & $\begin{array}{c}3.5(2.2 \\
4.8) \\
\end{array}$ & $4.9 \pm 2.3$ & $3.7 \pm 1.9$ & 0.0020 \\
\hline & Lap & $4.6(3.9,6)$ & $3(1.3,4.6)$ & $4.8 \pm 1.7$ & $3.1 \pm 1.9$ & $<0.0001$ \\
\hline \multirow{2}{*}{$\begin{array}{c}\text { Total } \\
\text { intraoperative } \\
\text { morphine } \\
\text { equivalents } \\
\text { (mg) }\end{array}$} & Open & $\begin{array}{c}56.7(33.4 \\
70.1)\end{array}$ & $\begin{array}{c}15(10, \\
25)\end{array}$ & $56.9 \pm 32.3$ & $\begin{array}{c}25.8 \pm \\
33.1 \\
\end{array}$ & $<0.0001$ \\
\hline & Lap & $\begin{array}{l}43.2(35.1 \\
60.2)\end{array}$ & $\begin{array}{l}15(10, \\
20)\end{array}$ & $47.5 \pm 19.1$ & $\begin{array}{c}16.9 \pm \\
10.4\end{array}$ & $<0.0001$ \\
\hline \multirow{2}{*}{$\begin{array}{c}\text { Total } \\
\text { postoperative } \\
\text { morphine } \\
\text { equivalents } \\
\text { (mg) }\end{array}$} & Open & $\begin{array}{c}171(63.4 \\
351)\end{array}$ & $\begin{array}{c}40(16.5 \\
134)\end{array}$ & $220 \pm 196$ & $\begin{array}{c}123 \pm \\
242\end{array}$ & $<0.0001$ \\
\hline & Lap & $\begin{array}{c}110.1(71.8, \\
162)\end{array}$ & $\begin{array}{c}20(6.7 \\
61.7)\end{array}$ & $159 \pm 179$ & $\begin{array}{c}53.7 \pm \\
74.5\end{array}$ & $<0.0001$ \\
\hline
\end{tabular}


Table 5A: Medical Costs (US \$)

\begin{tabular}{|c|c|c|c|c|c|c|}
\hline \multirow{2}{*}{$\begin{array}{l}\text { Hospital } \\
\text { Department } \\
\text { Groups }\end{array}$} & \multicolumn{2}{|c|}{ Medical costs } & \multirow{2}{*}{$\begin{array}{c}\text { Unadjusted } \\
\text { Difference } \\
\text { (ERAS - } \\
\text { traditional) }\end{array}$} & \multirow{2}{*}{$\begin{array}{l}\text { Lower } \\
\text { CI } \\
(95 \%)\end{array}$} & \multirow{2}{*}{$\begin{array}{c}\text { Upper } \\
\text { CI } \\
(95 \%)\end{array}$} & \multirow{2}{*}{$\begin{array}{l}\text { Unadjusted } \\
\text { P-Value }\end{array}$} \\
\hline & $\begin{array}{c}\text { Traditional } \\
(n=99)\end{array}$ & $\begin{array}{c}\text { ERAS } \\
(\mathrm{n}=142)\end{array}$ & & & & \\
\hline Non-ICU & 3121 & 2551 & -570 & -1074 & -66 & 0.027 \\
\hline ICU & 3251 & 2019 & -1232 & -2979 & 516 & 0.17 \\
\hline Pharmacy & 1350 & 853 & -497 & -946 & -47 & 0.03 \\
\hline $\begin{array}{l}\text { Medical and } \\
\text { Surgical } \\
\text { Supplies }\end{array}$ & 6380 & 7186 & 806 & -283 & 1896 & 0.15 \\
\hline Lab \& ECG & 1343 & 1018 & -325 & -671 & 21 & 0.07 \\
\hline Radiology & 411 & 404 & -7 & -282 & 269 & 0.96 \\
\hline OR + PACU & 3403 & 3383 & -19 & -260 & 222 & 0.88 \\
\hline Anesthesia & 248 & 234 & -14 & -32 & 5 & 0.14 \\
\hline Blood related & 251 & 139 & -112 & -270 & 47 & 0.17 \\
\hline Dialysis & 0 & 0 & 0 & & & \\
\hline Other & 776 & 579 & -197 & -743 & 350 & 0.48 \\
\hline Total & 20,537 & 18,377 & -2161 & -6352 & 2030 & 0.31 \\
\hline
\end{tabular}


Table 5B: Adjusted Medical Costs (\$, US)

\begin{tabular}{|l|c|c|c|c|}
\hline $\begin{array}{c}\text { Hospital } \\
\text { Department } \\
\text { Groups }\end{array}$ & $\begin{array}{c}\text { Adjusted } \\
\text { Difference } \\
\text { (ERAS - } \\
\text { traditional) }\end{array}$ & $\begin{array}{c}\text { Lower } \\
\text { CI } \\
\mathbf{( 9 5 \% )}\end{array}$ & $\begin{array}{c}\text { Upper } \\
\text { CI } \\
\mathbf{9 5 \% )}\end{array}$ & $\begin{array}{c}\text { Adjuste } \\
\text { d P- } \\
\text { Value }\end{array}$ \\
\hline Non-ICU & -509 & -1013 & -6 & 0.047 \\
\hline ICU & -1072 & -2834 & 691 & 0.23 \\
\hline Pharmacy & -463 & -914 & -12 & 0.044 \\
\hline $\begin{array}{l}\text { Medical and } \\
\text { Surgical } \\
\text { Supplies }\end{array}$ & 684 & -410 & 1778 & 0.22 \\
\hline Lab \& ECG & -265 & -612 & 82 & 0.13 \\
\hline Radiology & 16 & -263 & 295 & 0.91 \\
\hline OR + PACU & 20 & -220 & 261 & 0.87 \\
\hline Anesthesia & -12 & -30 & 7 & 0.21 \\
\hline Blood related & -89 & -249 & 71 & 0.27 \\
\hline Dialysis & -167 & -722 & 387 & 0.55 \\
\hline Other & & & & \\
\hline Total & -1854 & -6072 & 2363 & 0.39 \\
\hline
\end{tabular}

*Estimated differences and 95\% confidence intervals were adjusted for age, sex, and procedure type. 


\section{Legend}

Figure 1: Unadjusted cost savings

Cumulative distribution chart depicting the percent of bootstrap sample iterations in which the ERAS treatment strategy would be expected to be cost saving versus control using unadjusted values. 


\section{Supplementary Table 1. \\ Duke University Colorectal Surgery ERAS Protocol Summary}

\begin{tabular}{|c|c|}
\hline $\begin{array}{l}\text { PHASE OF CARE, } \\
\text { LOCATION }\end{array}$ & INTERVENTION \\
\hline $\begin{array}{l}\text { SURGICAL PLANNING, } \\
\text { SURGICAL CLINIC }\end{array}$ & $\begin{array}{l}\text { Identify elective surgery patients who can benefit from participation } \\
\text { Educate patients about the track and our expectations } \\
\text { Reinforce with a written copy of our plan and expectations } \\
\text { Screen for malnutrition, tobacco abuse, and diabetes (H\&P, labs) }\end{array}$ \\
\hline $\begin{array}{l}\text { PREOPERATIVE } \\
\text { ASSESSMENT, } \\
\text { PREOPERATIVE } \\
\text { ASSESSMENT CLINIC }\end{array}$ & $\begin{array}{l}\text { Routine preoperative screening, specific attention to known risk } \\
\text { factors } \\
\text { Distribute } \\
\text { - Nutritional supplements if serum albumin }<3.5 \\
\text { - Smoking cessation info } \\
\text { - Chlorhexidine sponges for } 2 \text { preoperative showers } \\
\text { Reinforce with written instructions }\end{array}$ \\
\hline $\begin{array}{l}\text { DAY OF OPERATION, } \\
\text { PREOPERATIVE } \\
\text { HOLDING AREA }\end{array}$ & $\begin{array}{l}\text { Identify ERAS patients and initiate protocol } \\
\text { Epidural anesthesia placement - T8-12 region } \\
\text { Thromboprophylaxis with heparin 5000U sc after placement of } \\
\text { epidural }\end{array}$ \\
\hline $\begin{array}{l}\text { INTRAOPERATIVE, } \\
\text { OPERATING ROOM }\end{array}$ & $\begin{array}{l}\text { Antibiotic prophylaxis before incision } \\
\text { Sequential compression devices placed before induction of anesthesia } \\
\text { Use epidural throughout case without any intravenous opioids } \\
\text { Goal-directed intravenous fluid therapy } \\
\text { Orogastric tube removed before leaving OR } \\
\text { Foley discontinued in OR, except for pelvic operations }\end{array}$ \\
\hline $\begin{array}{l}\text { POSTOPERATIVE CARE, } \\
\text { SURGICAL WARD }\end{array}$ & $\begin{array}{l}\text { Diet begins night of surgery } \\
\text { Ambulation begins night of surgery } \\
\text { Head of bed at } 30 \text { degrees at all times } \\
\text { Continue epidural for up to } 72 \text { hours postoperatively }\end{array}$ \\
\hline
\end{tabular}




\section{Supplementary Table 2.}

\section{Anesthesia colorectal enhanced recovery guidelines}

\begin{tabular}{|c|c|}
\hline INTVENTION & PROTOCOL \\
\hline THORACIC EPIDURAL & $\begin{array}{l}\text { T 8-12 region } \\
5000 \text { U subcutaneous heparin can be given after placement } \\
\text { Hydromorphone } 0.4 \mathrm{mg}-0.6 \mathrm{mg} \text { before induction of anesthesia } \\
\text { Lidocaine } 2 \% \text { bolus at least } 10 \text { minutes pre-incision }(40-100 \mathrm{mg}) \\
\text { Run infusion of } 0.25 \% \text { bupivacaine throughout case }(3-6 \mathrm{ml} / \mathrm{hr} \text {.) } \\
\text { No intraoperative iv opioids after induction without discussion with } \\
\text { the Attending Anesthesiologist } \\
\text { Switch to bupivacaine } 0.125 \% / \text { hydromorphone } 10 \mathrm{mcg} / \mathrm{ml} \mathrm{in} \mathrm{epidural} \\
\text { pump before leaving for PACU at end of case. } \\
\text { - Settings: Infusion } 4-6 \mathrm{ml} / \text { hour; } 2 \mathrm{ml} \text { bolus every } 30 \text { minutes }\end{array}$ \\
\hline $\begin{array}{l}\text { GOAL-DIRECTED FLUID } \\
\text { THERAPY }\end{array}$ & 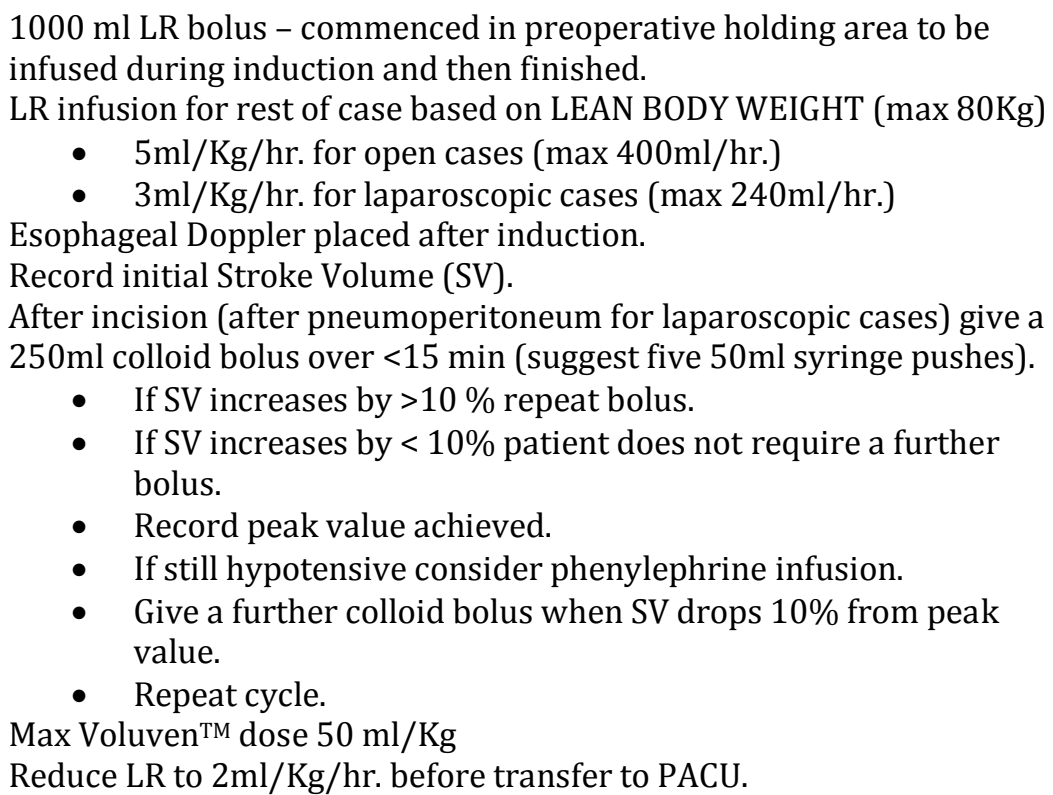 \\
\hline
\end{tabular}


Manuscript (All Manuscript Text Pages in MS Word format, including Title Page, References and Figure Legends)

Click here to download high resolution image

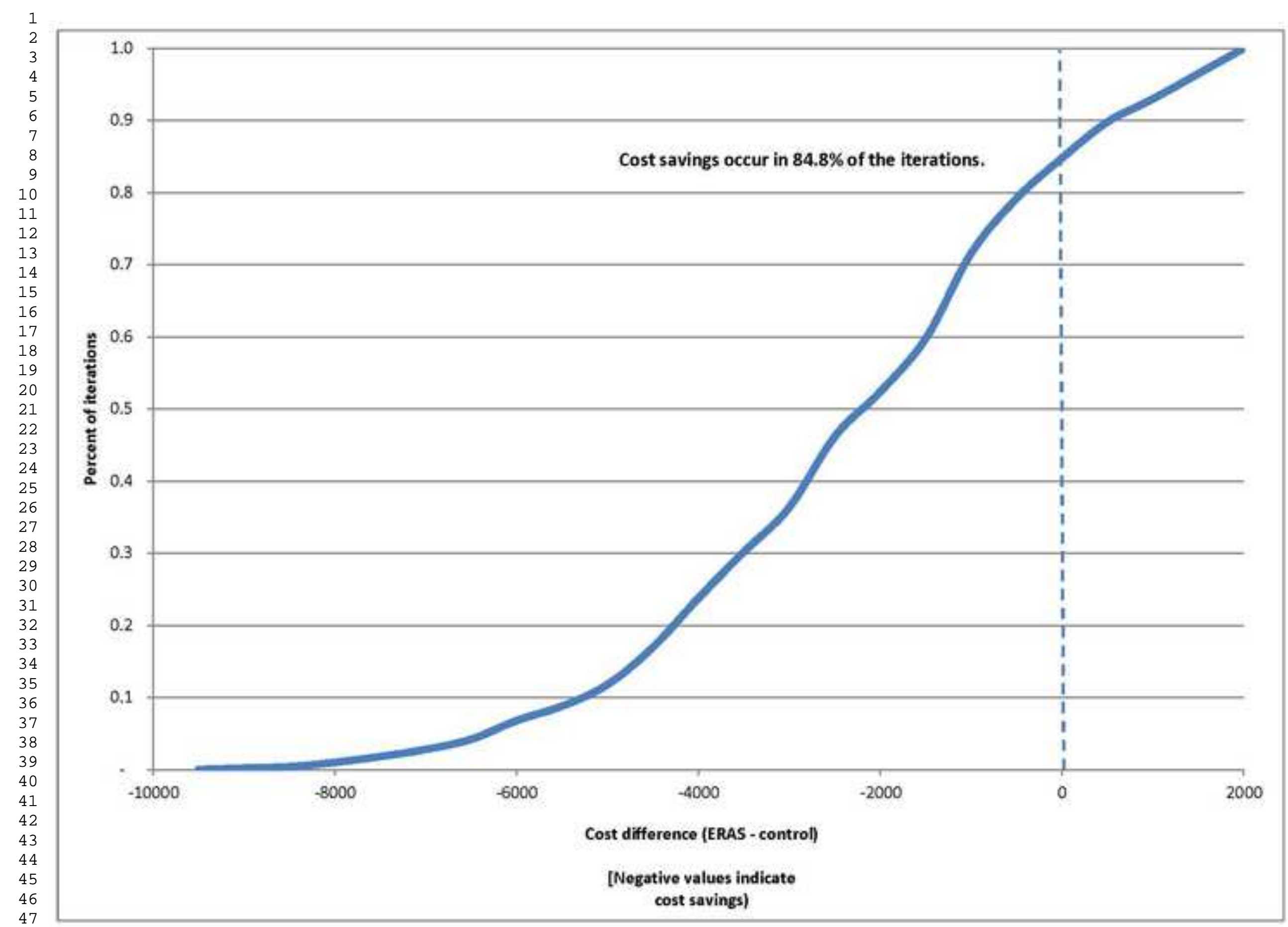

\section{cost savings)}

